RESEARCH / INVESTIGACIÓN

\title{
Potential effect of Imatinib on some sex hormones for male patients of Chronic Myelogenous Leukemia in Baghdad province
}

Abeer Anwer Ahmed ${ }^{1}$, Khaleed J Khaleel ${ }^{1}$, Alaa Abbas Fadhel ${ }^{2}$

DOI. 10.21931/RB/2021.06.04.9

Abstract: Imatinib Mesylate is an oral chemotherapy drug that has been used to treat Chronic Myelogenous Leukemia (CML). It works as an inhibitor of oncogene tyrosine kinase BCR-ABLI as a target therapeutic agent. Despite the drug is well tolerated in most patients, impaired testosterone production and Gynecomastia after therapy might happen. The current study aims to evaluate the impact of Imatinib Mesylate on sex hormones of CML male patients in Baghdad province. Blood specimens were collected from (42) CML patients aged 23 to 68 years who used Imatinib drug for more than two years, and (45) normal persons aged 25 to 65 years as a control group. Exclusion criteria were performed for both control and CML patient's groups, including people with diabetes, hypertensive, and males complaining of infertility after taking medical history for every participant. The blood level of hemoglobin (Hb), white blood cells (WBC), platelet count, testosterone, LH, and FSH were evaluated and investigated. The obtained results showed a significantly lower level of testosterone $(2.73+-0.97) \mathrm{ng} / \mathrm{mL}$ than the control group $(4.72 \pm 1.02) \mathrm{ng} / \mathrm{mL}$ with a p-value of 0.000 . While LH (4.53 \pm 2.1$) \mathrm{mlU} /$ $\mathrm{mL}$ and FSH (5.12 \pm 2.83$) \mathrm{mlU} / \mathrm{mL}$ were significantly higher than the control group $(3.77 \pm 0.8) \mathrm{mlU} / \mathrm{mL}$ and $(3.85 \pm 0.807) \mathrm{mlU} / \mathrm{mL}$ with p-value of 0.026 and 0.005 respectively. Moreover, the outcomes revealed a moderate positive correlation $(r=+0.348)$ between $\mathrm{LH}$ hormone levels with a duration increasing time of using Imatinib, while platelet showed a moderate negative correlation ( $r=-0.321)$ with time-consuming using that drug. In conclusion, Imatinib might harm testis functions and some hematological parameters that could increase using this drug.

Key words: Imatinib, Sex hormones, Myelogenous Leukemia, Patients.

\section{Introduction}

During the last two decades, the treatment of Chronic Myeloid Leukemia (CML) has changed because of the introduction of tyrosine kinase inhibitor. The survival rate had been increased in patients with Leukemia and lymphoma ${ }^{1}$. Besides that, the infertility complications were raised in parallel with that disease. The chance of getting CML can be increased at the 4th decade of life or a younger age group where reproductive functions are crucial in affected men ${ }^{2,3}$. It has been identified many side effects about sexual function by using drugs for CML therapy. However, CML as a disease may adversely affect male fertility even before any therapy ${ }^{4,5}$. The introduction of tyrosine kinase inhibitor has increased the survival rate significantly, highlighting issues related to the quality of life with an important area of fertility and paternity. The gonadal dysfunction induced by therapy depends in general on age dosages and types of the therapies used in CML treatment ${ }^{6}$.

Moreover, animal studies on Imatinib using standard dosages have shown non significantly impaired adult male fertility ${ }^{4-7}$. The effect of Imatinib on spermatogenesis seems to be dose dependably ${ }^{8}$. c-KIT is essential for developments of Leydig cells and migration survival and proliferation of spermatogonia. Also, Platelets derived growth factors (PDGF) and (PDGF-R) are very important for developing Myeloid and Leydig cells ${ }^{9}$. This study aimed to investigate the potential testicular effects of using imatinib drugs for CML patients (testicular Leydig cell function and androgen status) by measuring and characterizing reproductive hormones such as Follicle-stimulating Hormone (FSH), Luteinizing Hormone (LH), and testosterone.

\section{Materials and methods}

The investigation was a spin-off study for (42) male pa- tients with CML that attended the National center for hematological diseases at Al-Mustanseria University. Participant patients have been using a standard dose of $400 \mathrm{mg}$ of tyrosine kinase inhibitor (Imatinib) per day for equal or more than two years, and their ages ranged from 23 years to 68 years old. Patients in the above center that included in this spin-off protocol were invited to participate in this study only if they already agreed to be included. A healthy control group of (45) males aged 25 years to 65 was also involved. Exclusion criteria for both control and CML patients groups were performed for people with diabetes, hypertensive, and males complaining of infertility after taking medical history for each one. Blood samples were taken from both groups. Blood specimens were collected in EDTA tubes for $\mathrm{Hb}$, white blood cells, platelets, and differential count for WBC analysis. The mentioned hematological parameters were estimated using an electronic counter (Mandray Company, France), and the blood films were performed on all patients and control groups using Giemsa stain. In addition, gel tubes were used to assess LH, FSH, and testosterone hormones concentrations by using the ELISA method through a micro plate reader (AWARENESS, USA). The ELISA kits were DRG from Germany.

\section{Statistical Analysis}

All statistics in the present study were performed by using SPSS Ver. 23 for windows. Quantitative values were presented as Mean and Standard deviation (SD) of all variables. An independent t-test was used to exhibit the significance of differences. The confidence interval (95\%) p-value $£ 0.05$ was considered statistically significant, while the probability $p$-value $>$ 0.05 indicates statistically not significant. Moreover, correlation analysis between parameters was assessed by Pearson's.

\footnotetext{
Iraqi Center for cancer and medical genetics research// Al-Mustansiriyah University, Iraq.

${ }^{2}$ Al- Mussaib Technical College / Al-Furat Al-Awsat Technical University, 51009, Babylon, Iraq.
} 


\section{Results and discussion}

Nowadays, the new molecular design of cancer treatments such as tyrosine kinase inhibitors can be applied into therapy, and the strategy for young adults and children and the latent effect on testis functions should be considered. The role of these drugs in some of specific physiological signals cascade modulated may be varied with the maturation state and age, and the effectiveness and the side effects of these agents in young adults and children may be different. It is well known that the introduction of the tyrosine kinase inhibitor has revolutionized the therapy of CML that leads to prolonged survival and significant improvement in the quality of life that results in increasing the number of patients that wish to be the father. According to previous animal studies on the effect of tyrosine kinase inhibitor as treatment, there is a mild to moderate impairment of the male reproductive system ${ }^{10-12}$.

In general, hormones act upon the phases of the spermatogenesis (like LH and FSH) act directly on the testis to stimulate somatic cells functions that support spermatogenesis ${ }^{13}$. It had been reported that FSH is mainly regulated spermatogonial development ${ }^{14,15}$, while $\mathrm{LH}$ is working on Leydig cell to secrete testosterone. In the case of testosterone, it is the primary male steroid sex hormone and plays a crucial role in developing male reproductive tissue such as testis and prostate as well as secondary sexual characteristics ${ }^{16}$. Testosterone regulates the later phase of spermatogenesis, which takes about 74 days. Despite semen analysis not being performed in the current study, however, there is an effect of Imatinib on tail protein PY phosphorylation in human is related to sperm motility. The deficiency of this protein during therapy with tyrosine kinase inhibitor (Imatinib) may be associated with decreased motility of the sperm ${ }^{17-20}$. For hematological edge, the present study showed that platelets count is significantly higher than the control group $(13.81 \pm 1.28)$ and $(13.70 \pm 0.79)$, respectively, with $p$-value of 0.03 . Even though the patients and control group are within the normal range, our explanation regarding these results may be due to the small sample size. While for $\mathrm{Hb}$ and WBC account the obtained result exhibited that the is non-significant differences between health and the patient group were $\mathrm{Hb} 13.70 \pm 0.79(\mathrm{~g} / \mathrm{dL})$ and $13.81 \pm 1.28(\mathrm{~g} / \mathrm{dL})$, and $5.88 \pm 1.21,6.81 \pm 3.39$ for WBc respectively), Table 1 .

The results of the hormonal, biochemical assay showed in the case of testosterone that the mean level of the patient's group $(2.73 \pm 0.97) \mathrm{ng} / \mathrm{mL}$ is significantly lower than the con- trol group $(4.72 \pm 0.72) \mathrm{ng} / \mathrm{mL}$ with $\mathrm{p}$-value of $(0.00)$ this finding is consistent with several studies ${ }^{14,15}$. Also, the LH hormone in the patient's group is significantly higher than the control group $4.53 \pm 2.1 \mathrm{mlU} / \mathrm{mL}$ and $3.77 \pm 0.8 \mathrm{mlU} / \mathrm{mL}$, respectively, with $p$-value 0.026 . The same is true for FSH hormone; the patient's group is also significantly higher than the health group $5.12 \pm 2.83 \mathrm{mlU} / \mathrm{mL}$ and $3.85 \pm 0.807 \mathrm{mlU} / \mathrm{mL}$, respectively, $\mathrm{p}$-value 0.005 . our results were different from that reported by (21). However, our data is consistent with that reported (22).

The correlation for all measured parameters with duration increasing time for Imatinib was assessed. Regarding that, the results showed a moderate positive correlation ( $r=+0.348)$ of $\mathrm{LH}$ hormone with increasing time duration of the mentioned treatment with $p$-value 0.026 as shown in table 3 . while for platelet number, the results exhibited that there is a moderate negative correlation ( $r=-0.321$ ) with increasing time consumed of the Imatinib drug with p-value (0.038). For all other parameters, the outcomes revealed that there is a non-significant correlation with duration consuming time, this is maybe due to our results dealing with a small number of samples. However, these results are consistent with that reported by (23) that stated Imatinib decreases the viability of normal Leydig cells in a manner not time-dependent. Moreover, Imatinib has an antiangiogenic effect that inhibits the vascular endothelial growth factor ${ }^{23,24}$. Imatinib delays or may block migration of gonocytes from the center of the seminiferous cord to basement members to form a spermatogonial stem cells pool. Inhibition of migration was probably due to blockage of the c-kit receptor. The presence of c-kit antiserum in Sertoli cells inhibits migration of gonocytes ${ }^{25,26}$. Imatinib interferes with several maturation processes in the rat-like spermatogonial stem cell and Leydig cells that produce testosterone and proliferation of differentiation type A spermatogonial. The low testosterone level is derived from the hypothalamus pituitary axis and LH; FSH levels will increase significantly secondary to low testosterone levels ${ }^{27}$.

\section{Conclusions}

The therapy of tyrosine kinase inhibitor for male CML patients adversely affects testosterone levels with increased LH and FSH levels. However, it is unlikely to knock down the sperms production. It is advisable to have sperm banking in young adult patients before starting prolonged treatment by Imatinib

\begin{tabular}{|c|c|c|c|}
\hline Parameters & Mean \pm SD control & Mean \pm SD patients & p-Value \\
\hline Hb (g/dL) & $13.70 \pm 0.79$ & $13.81 \pm 1.28$ & Ns \\
\hline $\mathbf{W B c}(\mathbf{1 0} / \mathbf{L})$ & $5.88 \pm 1.21$ & $6.81 \pm 3.39$ & Ns \\
\hline Platelet $(\mathbf{1 0} / \mathbf{L})$ & $208.88 \pm 39.72$ & $231.71 \pm 57.31$ & 0.03 \\
\hline
\end{tabular}

Ns : Non-significant

Table 1. Hematological parameters for patients and control health group

\begin{tabular}{|l|l|l|l|}
\hline Parameters & Mean \pm SD control & Mean \pm SD patients & p-Value \\
\hline FSH $(\mathbf{m I U} / \mathbf{m L})$ & $3.85 \pm 0.807$ & $5.12 \pm 2.83$ & 0.005 \\
\hline LH $(\mathbf{m I U} / \mathbf{m L})$ & $3.77 \pm 0.8$ & $4.53 \pm 2.1$ & 0.026 \\
\hline $\begin{array}{l}\text { Testosterone } \\
(\mathbf{n g} / \mathbf{m L})\end{array}$ & $4.72 \pm 0.72$ & $2.73 \pm 0.97$ & 0.000 \\
\hline
\end{tabular}

Table 2. Hormonal biochemical parameters for patients and control groups 


\begin{tabular}{|l|c|l|}
\hline Parameters & Correlation coefficient (r) & p-value \\
\hline LH & +0.348 & 0.026 \\
\hline Platelet & -0.321 & 0.038 \\
\hline
\end{tabular}

Table 3. The correlation coefficient of some parameters with increasing consuming time of Imatinib drug.

that can be easily applied. However, the present study's limitation is the small sample size of CML patients included in the present data. A larger sample size is highly recommended to enforce those original results. Also, seminal fluid analysis was not done because most patients were unwilling to provide us with their semen.

\section{Bibliographic references}

1. Raanani P. Granot G. , Ben- Bassam., cure of chronic Myeliod Leukemia in the third millennium a down to earth target (ed.) or a castle in the air. Cancer Lett pil (2014), 50304 - 3835(14)

2. Menon $\mathrm{H}$., Issues in the current management of Chronic Myeliod Leukemia. Importance of molecular monitoring on long term outcome. South Asian J. Cancer (2013), 2: 38-43.

3. Krause DS, VanEtten RA., Tyrosine kinases as targets for cancer therapy, N. Eng. J Med. (2005) 353:172-187.

4. Chuah C., Imatinib does not impair gonadal function. Leu. Res (2012),36:262-263.

5. Hensley ML. Ford J.M., Imatinib treatment; specific issues related to to safety, fertility and pregnancy. Semin Hematol. (2003), 40: 21-25.

6. Borker A. Advani S.H., Testicular involvement in blast crisis of Chronic Myeliod Leukemia. Indian Pediatric (2005) 42:1166-1167.

7. Ault P. Kantarjan H, O.Brien S, Federl S., Beran M., Pregnancy Among patients with chronic Myeliod Leukemia treated with Imatinib J.clin. Oncol (2006), 24:1204-1208.

8. Mariani S. Basciani S. Arrizzi M., Spera G. Gnessi L., PDGF And the testis. Trends Endocrinol. Metab. (2002):13; 11-17.

9. Nurmio M. Toppari J. Zaman F. Anderson AM., Paraniko J.Inhibition of tyrosine kinases PDGFR and c-kit by Imatinib Mesylate interferes with postnatal testicular development in the rat Int. J.Androl. (2007), 30:366-376.

10. Shash E. Bassi S. Cocorocchio E, Colpi GM, I S., Fatherhood during Imatinib. Acta Oncol (2011), 50:734-735.

11. Gambacorti-Passerini C. Torgnaghi L. Cavagnini F, Rossi P.Gynecomastia in men with chronic Myeliod Leukemia after Imatinib. Lancet (2003), 361:1954-1956.

12. Kierszenbaum AL. Tyrosine protein kinase and spermatogenesis truncation matters. Mol.Repord Dev (2006), 73:399-403.

13. Holdcraft R.W, Braun RE., Hormonal regulation of spermatogenesis Int. J. Androl. (2004), 27:335-342.

14. Johnson M.S., Wilbers W.B., Nobel J. Fennel M., Mitchel R., Effect of tyrosine kinase inhibitors on luteinizing hormone releasing hormone $(\mathrm{LHRH})$ induced gonadotropin released from ant. Pituitary molecular cell Androcrin. (1995),109: 69-75.

15. Opalka DM. Kamiska B. Ciereszko R. Dusza I. Genistein effect testeron secretions by Leyding cells in roosters Reproductive. Biology (2004), 4: 185-193.

16. Opalika DM Kaminska B. Psiskula MK. Puchajda-Skoronsia H. Dusza I., Effect of phytoestrogens on testeron secretion by Lyding cells from Bilgoraji genders Br Pult Sci (2006), 47:237-245.

17. Bajpai M. As in S. Doncel G.F., Effect of tyrosine kinase inhibitor on tyrosine phosphorylation and motility parameters in human sperm. Arch Androl. (2003), 49:229-246.

18. Yeung $\mathrm{CH}$ Sonnenberg- Riethmacher E. Cooper T.G., Infertile spermatozoa of c-ros tyrosine kinase receptors knockouts mice show flageller angulation and maturational effect in cell volumes regulatory mechanisms. Bio. Reprod .(1999), 61:1062-1069.

19. Bajpai M. Doncel GF. involvement of tyrosine kinase and cAMP-dependent kinase cross talk in the regulation of human sperm motility Reproduction (2003),126:183-195.

20.Tash J.S. Bracho G.E., Identification of Phosphoproteins coupled to initiation of motility in live epididymal mouse sperm biochemical. Biopsy's Res. commun. (1998), 251:557-563.

21. Al-Dewik, Nader I., et al. "Molecular monitoring of patients with chronic myeloid leukemia (CML) in the state of Qatar: optimization of techniques and response to imatinib." QScience Connect 2014.1 (2014): 24.

22. YAGHMAEI, PARICHEHR, et al. "The biological effects of imatinib on male fertility of Wistar rats." (2009): 135-142.

23. Kheradmand F. , Hashemnia S., Valizadeh N., Milano S., The effects of Imatinib Mesylate on cellular viability, platelet derived Growth factor and stem cell factor in Mouse Testicular normal Leydig cells. J. Reprod. Infertility (2016), 17(2):82-87.

24. Khaleel KJ, Fadhel AA, Mohammad MH. Potential effects of hypoglycemic and non-steroidal anti-inflammatory drugs on breast cancer (Mcf-7) cell line. International Journal of Pharmaceutical Research. 2020 Sep;12:1620-4.

25. Eckman A. Dogs A., Drug induced Gynecomastia Exposing Drug saf. (2008), $7: 691-702$

26. Khaleel, K. J., Fadhel, A. A., \& Al-Hindawi, M. M. Prostate Specific Antigen As Screening Test a Hospital-Based Study. Biochemical and Cellular Archives, (2020). 20(2), 5691-5693.

27. Orth J. M. Quick J. Jester, W.F. Jr Pilder., Expression of the c-kit gene is critical for migration gonocytes in vitro biology of reprod. (1997), 57, 676-683.

Received: 26 September 2021

Accepted: 23 October 2021 